\title{
Cdc7-Drf1 kinase links chromosome cohesion to the initiation of DNA replication in Xenopus egg extracts
}

\author{
Tatsuro S. Takahashi, ${ }^{1,3,5}$ Abhijit Basu, ${ }^{2}$ Vladimir Bermudez, ${ }^{2}$ Jerard Hurwitz, ${ }^{2}$ \\ and Johannes C. Walter ${ }^{1,4}$ \\ ${ }^{1}$ Biological Chemistry and Molecular Pharmacology, Harvard Medical School, Boston, Massachusetts 02115, USA; \\ ${ }^{2}$ Memorial Sloan-Kettering Cancer Center, New York, New York 10065, USA
}

\begin{abstract}
To establish functional cohesion between replicated sister chromatids, cohesin is recruited to chromatin before $S$ phase. Cohesin is loaded onto chromosomes in the G1 phase by the Scc2-Scc4 complex, but little is known about how Scc2-Scc4 itself is recruited to chromatin. Using Xenopus egg extracts as a vertebrate model system, we showed previously that the chromatin association of Scc2 and cohesin is dependent on the prior establishment of prereplication complexes (pre-RCs) at origins of replication. Here, we report that Scc2-Scc4 exists in a stable complex with the Cdc7-Drf1 protein kinase (DDK), which is known to bind pre-RCs and activate them for DNA replication. Immunodepletion of DDK from Xenopus egg extracts impairs chromatin association of Scc2-Scc4, a defect that is reversed by wild-type, but not catalytically inactive DDK. A complex of Scc4 and the $\mathbf{N}$ terminus of Scc2 is sufficient for chromatin loading of Scc2-Scc4, but not for cohesin recruitment. These results show that DDK is required to tether Scc2-Scc4 to pre-RCs, and they underscore the intimate link between early steps in DNA replication and cohesion.
\end{abstract}

[Keywords: Cdc7-Drf1; DNA replication; Xenopus; cohesin; cohesion; Scc2-Scc4]

Supplemental material is available at http://www.genesdev.org.

Received April 10, 2008; revised version accepted May 23, 2008.

Chromosomal DNA is duplicated in the S phase of the cell cycle and distributed to daughter cells in mitosis. Cohesion of sister chromatids is crucial for precise segregation of chromosomes, as it marks sister chromosomes to be separated. Cohesion is established by the ring-shaped cohesin complex, which consists of two structural maintenance of chromosome (SMC) family proteins, Smc1 and Smc3, an $\alpha$-kleisin subunit, Rad21/Scc1, and an accessory protein, SA/Scc3 (for review, see Huang et al. 2005; Nasmyth and Haering 2005; Hirano 2006; Losada 2007). Several lines of evidence suggest that cohesion is established when replicated sister chromatids are both entrapped within the cohesin ring (Ivanov and Nasmyth 2005, 2007), but alternative models also exist (Milutinovich et al. 2007). Proteolytic cleavage of Scc1 by separase at the metaphase-anaphase transition releases cohesins from chromatin, enabling sister chromatids to move to each daughter cell (Uhlmann et al. 2000). In metazoans, cohesins associated with the chromosome

\footnotetext{
${ }^{3}$ Present address: Department of Biological Science, Graduate School of Science, Osaka University, 1-1 Machikaneyama-cho, Toyonaka, Osaka 560-0043, Japan

Corresponding authors.

${ }^{4}$ E-MAIL johannes walter@hms.harvard.edu; FAX (617) 738-0516

${ }^{5}$ E-MAIL tatsuro_takahashi@bio.sci.osaka-u.ac.jp; FAX 81-6-6850-5440.

Article is online at http://www.genesdev.org/cgi/doi/10.1101/gad.1683308.
}

arms are removed in prophase by phosphorylation of the SA subunit via polo-like kinase (Sumara et al. 2000; Waizenegger et al. 2000; Losada et al. 2002; Hauf et al. 2005). The remainder of chromosome-linked cohesins is cleaved at the metaphase-anaphase transition by separase.

The process of cohesion establishment is intimately connected to DNA replication. Experiments in yeast show that the establishment of cohesion in S phase requires that cohesin be present on chromatin during DNA replication (Uhlmann and Nasmyth 1998; Lengronne et al. 2006). The Ctf7/Ecol protein, which physically and genetically interacts with PCNA and RFC (Kenna and Skibbens 2003; Moldovan et al. 2006), is required for establishment of cohesion in S phase (Skibbens et al. 1999; Toth et al. 1999). Two other nonessential proteins that are involved in cohesion, Ctf4 and Ctf18 (Hanna et al. 2001; Mayer et al. 2001), show strong ties to the replication machinery. Ctf4 associates with DNA polymerase $\alpha /$ primase, and is part of a replisome progression complex (Miles and Formosa 1992; Gambus et al. 2006). Ctf18 forms an alternative RFC complex with Rfc2-5 and loads PCNA onto DNA (Bermudez et al. 2003). These findings not withstanding, the precise mechanism of cohesion establishment in S phase is unknown.

In addition to the factors described above, which promote cohesion establishment in S phase, a complex com- 
posed of Scc2 and Scc4 is required for the recruitment of cohesin to chromosomes, as first shown in budding yeast (Ciosk et al. 2000). Orthologs of yeast Scc2 were readily identified in other eukaryotes including human, Xenopus, Drosophila, and fission yeast (Furuya et al. 1998; Gillespie and Hirano 2004; Krantz et al. 2004; Rollins et al. 2004; Takahashi et al. 2004; Tonkin et al. 2004). In contrast, due to weak evolutionary conservation of its primary structure, orthologs of Saccharomyces cerevisiae Scc4 have been identified only recently (Bernard et al. 2006; Seitan et al. 2006; Watrin et al. 2006). The mechanism by which Scc2-Scc4 promotes cohesin loading is not understood, but it appears to involve chromatin recruitment of Scc2-Scc4 itself (Gillespie and Hirano 2004; Takahashi et al. 2004). Although Scc2-Scc4-binding sites have been identified recently in yeast and flies (Lengronne et al. 2004; Misulovin et al. 2008), it is not known how the complex is recruited to these sites.

Eukaryotic DNA replication is initiated via the ordered recruitment of numerous factors onto replication origins (for review, see Bell and Dutta 2002). In the G1 phase, the Mcm2-7 complex is loaded onto chromatin by the origin recognition complex (ORC), Cdc6, and Cdt1, resulting in formation of a prereplication complex (pre$\mathrm{RC})$. At the onset of S phase, the Mcm2-7 helicase is activated by several replication factors, including the Cdc7 protein kinase and the S-phase cyclin-dependent kinase (S-CDK) (Sclafani 2000; Masai and Arai 2002; Tanaka et al. 2007; Zegerman and Diffley 2007). These protein kinases promote loading of initiation factors such as Cdc45 and GINS (Jares and Blow 2000; Walter 2000; Zou and Stillman 2000; Kubota et al. 2003; Takayama et al. 2003; Masai et al. 2006), which are putative cofactors for the Mcm2-7 helicase (Pacek and Walter 2004; Moyer et al. 2006; Pacek et al. 2006). Once the origin is unwound by the Mcm2-7 complex, replisomes assemble and DNA synthesis can commence.

The Cdc7-kinase directly phosphorylates the Mcm2-7 complex, stimulating association of downstream factors such as Cdc45 (Sclafani 2000; Masai and Arai 2002; Masai et al. 2006; Montagnoli et al. 2006; Sheu and Stillman 2006). Like CDK, Cdc7 requires a regulatory subunit to activate its kinase activity. In yeast, this function is performed by Dbf4 (Jackson et al. 1993). Vertebrates contain two related Cdc7 activators, Dbf4 and Drf1 (Montagnoli et al. 2002; Yanow et al. 2003; Yoshizawa-Sugata et al. 2005). Cdc7-Dbf4 and Cdc7-Drf1 are often referred to as DDK (Dbf4- or Drf1-dependent kinase). During Xenopus early embryogenesis, Drf1 is the predominant activator of Cdc7, while in somatic cells, Dbf4 likely plays a more prominent role (Takahashi and Walter 2005; Silva et al. 2006).

Xenopus egg extracts represent a powerful model system for studying the mechanism of sister chromatid cohesion in vitro (Losada et al. 1998; Waizenegger et al. 2000). In these extracts, recruitment of Scc2 and cohesin to chromatin requires the presence of pre-RCs /Gillespie and Hirano 2004; Takahashi et al. 2004), but it is independent of Cdk2 activity (S-CDK), and therefore occurs upstream of replication initiation. Thus, in Xenopus early embryos, chromatin association of Scc2 is intimately linked to early events in DNA replication. To better understand how cohesin loading is linked to DNA replication, we explored further the mechanism of Scc2-Scc4 chromatin association in Xenopus egg extracts. Unexpectedly, we found that Scc2-Scc4 forms a tight complex with DDK, and that the protein kinase activity of DDK is essential for Scc2-Scc4 recruitment to chromatin.

\section{Results}

Xenopus Scc2-Scc4 is required for pre-RC-dependent association of cohesins with chromatin

When crushed by centrifugation, unfertilized eggs of the frog Xenopus laevis yield a low speed supernatant of egg cytoplasm called LSS (Blow 1993). Demembranated sperm chromatin added to LSS is assembled into nuclei that undergo DNA replication. Concurrently, cohesins are recruited to chromatin and cohesion is established between replicated sister chromatids (Losada et al. 1998). To characterize Scc4 in this system, we cloned Xenopus Scc4 using the human sequence (see the Materials and Methods). We expressed Xenopus Scc4 in bacteria and used the purified protein to immunize rabbits. Using Western blotting, the affinity-purified antibody readily recognized 200 pg of recombinant Scc4 purified from insect cells, and in a Xenopus nucleoplasmic extract (NPE) (Walter et al. 1998), it detected a single prominent band of $68 \mathrm{kDa}$ (Supplemental Fig. S1). This 68-kDa protein was significantly enriched in NPE relative to LSS, indicating that it is enriched in nuclei (Supplemental Fig. S1). Immunoprecipitation (IP) with the Scc4 antibody precipitated the vast majority of the $68-\mathrm{kDa}$ protein from LSS, and it also codepleted almost all of the endogenous Scc2 protein (Fig. 1A, lanes 3,6). Similarly, IP of Scc2 removed the great majority of Scc2 from the extract (Takahashi et al. 2004), and it coprecipitated most of the $68-\mathrm{kDa}$ protein (Fig. 1A, lanes 2,5). Based on these and other results presented below, we conclude that the 68$\mathrm{kDa}$ protein is Xenopus Scc4. The IP experiments indicate that in interphase egg extracts, the vast majority of Scc2 and Scc4 reside in a complex with each other. Scc2 and Scc4 also associated in M-phase egg extracts, suggesting that the interaction is independent of the cell cycle phase (Supplemental Fig. S2).

Scc2 is essential for chromatin association of cohesin in Xenopus egg extracts, and its chromatin loading requires assembly of the pre-RC (Gillespie and Hirano 2004; Takahashi et al. 2004). As most Scc4 associates with Scc2, we expected that Scc4 would also be involved in pre-RC-dependent cohesin loading. To test this idea, we immunodepleted Scc2 or Scc4 from Xenopus egg extracts and examined chromatin association of Scc2, Scc4, and cohesin. Depletion of Scc2 completely inhibited chromatin association of Scc4 and significantly reduced that of Rad21, a subunit of cohesin (Fig. 1B, lanes 3,4). Similarly, depletion of Scc 4 abolished chromatin association of Scc2, and impaired that of Rad21 (Fig. 1B, lanes $5,6)$. We next asked whether chromatin association of 
Figure 1. Xenopus Scc2-Scc4 is required for preRC-dependent cohesin recruitment to chromatin. (A) IP was performed with control (lanes 1,4), anti-Scc2 (lanes 2,5), or anti-Scc4 antibody (lanes $3,6)$ from LSS. Supernatants (IP-sup; lanes 1-3) or immunoprecipitates (IP-ppt; lanes 4-6) were probed with Scc2 (top panel) or Scc4 (bottom panel) antibody. $\left({ }^{\star}\right)$ Cross-reacting band. $(B)$ Sperm chromatin was incubated in mock-depleted (lanes 1,2), Scc2-depleted (lanes 3,4), or Scc4-depleted LSS (lanes 5,6), and isolated at the indicated times. Chromatin-bound proteins were probed with the indicated antibodies. $\left({ }^{*}\right)$ Cross-reacting band. $(C)$ Sperm chromatin was incubated in either mock-depleted (lane 1) or Cdt1-depleted LSS (lane 2) and isolated after $90 \mathrm{~min}$. Chromatinbound proteins were probed with the indicated antibodies. $\left({ }^{*}\right)$ Cross-reacting band. (D) IVT-expressed Xenopus Scc2(1-1024) (lanes 3-5), IVTexpressed Scc4 (lanes 2,4,5), or unprogrammed IVT lysate $(2.5 \mu \mathrm{L}$ of each) was added to $10 \mu \mathrm{L}$ of HSS. Sperm chromatin was added to the HSS-IVT mixture at $10,000 / \mu \mathrm{L}$ concentration relative to HSS (lanes 1-4) and isolated after $30 \mathrm{~min}$. Chromatin-bound proteins were probed with the indicated antibodies.
A

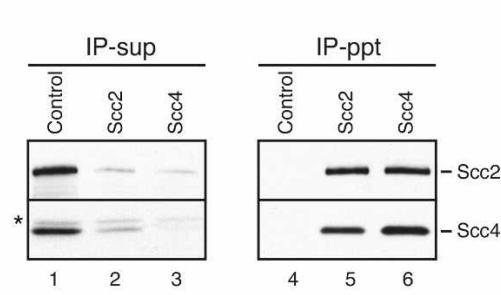

B

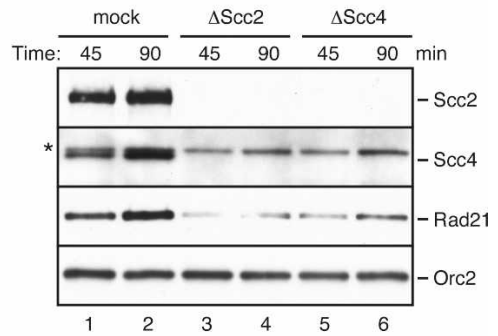

C
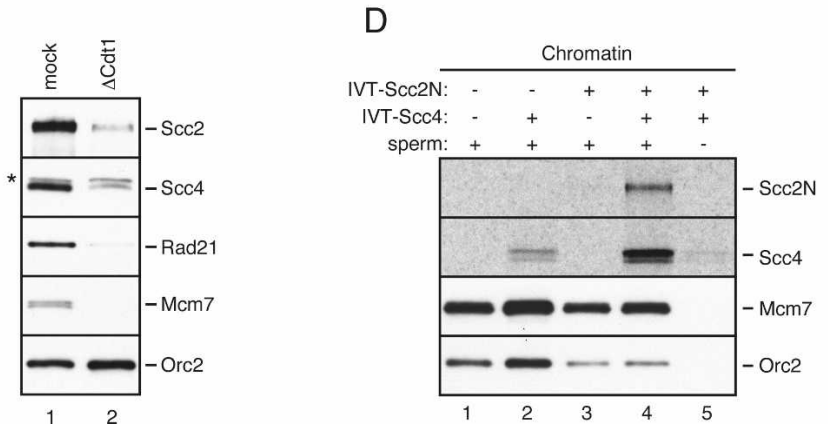

Scc4, like that of Scc2, is dependent on the pre-RC. Inhibition of pre-RC formation by depletion of Cdt1 severely reduced chromatin association of Scc4, as well as that of Scc2, Rad21, and Mcm7 (Fig. 1C; Takahashi et al. 2004). Overall, these results indicate that Xenopus Scc2Scc4 is loaded onto chromatin by pre-RCs, whereupon it promotes chromatin loading of cohesin.

\section{A complex of Scc4 and the $N$ terminus of Scc2 binds to chromatin}

We next examined which regions of Scc2 and Scc4 are required for Scc2-Scc4 complex formation and for chromatin association. Using Scc2 and Scc4 fragments expressed in in vitro transcription-coupled translation (IVT) system, we found that the $\mathrm{N}$-terminal 485 amino acids of Scc2 $\left(\operatorname{Scc} 2^{1-485}\right)$ interacted stably with the $\mathrm{N}$ terminal 205 amino acids of Scc4 $\left(S c c 4^{1-205}\right.$ ) (Supplemental Fig. S3). While this work was in progress, similar results were reported for human Scc2 and Scc4 using two-hybrid analysis (Seitan et al. 2006).

To test which domains of Scc2-Scc4 are responsible for chromatin association, IVT-expressed Scc2 and Scc4 fragments were added to a high-speed supernatant (HSS) of Xenopus eggs. HSS supports pre-RC assembly but not DNA replication, since it lacks nuclear membrane vesicles, and therefore does not support nuclear envelope formation. When added alone, no significant chromatin binding of either Scc2 $2^{1-1024}$ or full-length Scc4 was observed (Fig. 1D, lanes 1-3, note that lane 2 is overloaded). Similarly, other regions of Scc2 did not show significant chromatin binding (data not shown). In contrast, Scc2 ${ }^{1-1024}$ and Scc4 clearly bound to chromatin when they were mixed together (Fig. 1D, lane 4). Scc $2^{1-485}$ also bound to chromatin when Scc4 was present (data not shown). The data suggest that the chromatin-binding module of Scc2Scc4 involves a complex of Scc4 and the $\mathrm{N}$ terminus of $\operatorname{Scc} 2$.

\section{Scc2-Scc4 physically interacts with Cdc7-Drf1 and Cdc7-Dbf4}

We and others previously showed that in Xenopus egg extracts, chromatin binding of DDK is pre-RC-dependent and Cdk2-independent (Jares and Blow 2000; Walter 2000; Jares et al. 2004; Takahashi and Walter 2005). Since Scc2-Scc4 binding to chromatin shows the same characteristics (Takahashi et al. 2004) (see introduction section, above), we suspected that chromatin loading of DDK and Scc2-Scc4/cohesin might be linked.

To test whether DDK is involved in chromatin association of Scc2-Scc4, we immunodepleted Cdc7, which removes the vast majority of Cdc7, Drf1, and Dbf4 from the egg extracts (Takahashi and Walter 2005). As we reported previously (Takahashi and Walter 2005), depletion of $\mathrm{Cdc} 7$ reduced the rate of DNA replication to $<50 \%$ of that seen in mock-treated extract (Fig. 2B), and it significantly reduced phosphorylation of $\mathrm{Mcm} 4$ on chromatin (Fig. 2A, panel IV, cf. lanes 1 and 3). Strikingly, depletion of Cdc7 markedly reduced chromatin association of Scc2, Scc4, and Rad21 (Fig. 2A, panels I-III, lanes 1-4). However, addition of recombinant Cdc7-Drf1 (rCdc7-Drf1) only weakly rescued loading of Scc2-Scc4 or Rad21 (Fig. 2A, panels I-III, lanes 5,6), even though it restored efficient Mcm4 phosphorylation (Fig. 2A, panel IV, lane 5) and DNA replication (Fig. 2B). The amount of chromatin-associated recombinant $\mathrm{Cdc} 7$ was comparable with that observed with the endogenous protein (Fig. 2A, panel VII, cf. lanes 1,2 , and 5,6), showing that we used a near physiological concentration of rCdc7-Drf1. 
A

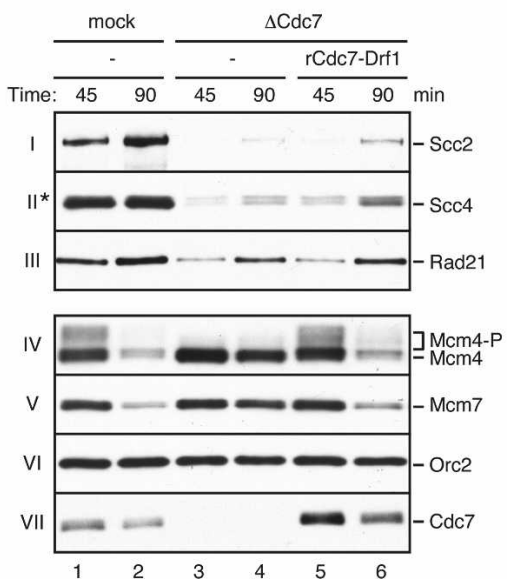

B

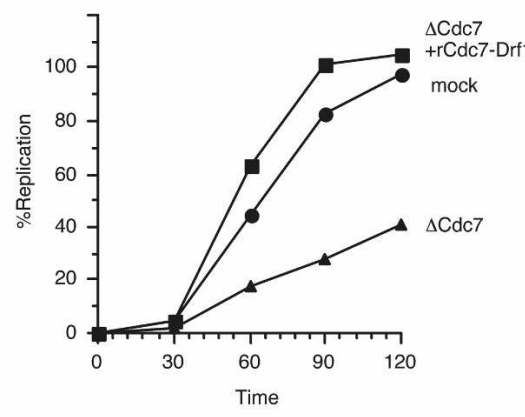

Figure 2. Cdc7-depletion impairs chromatin association of the Scc2-Scc4 complex. $(A)$ Sperm chromatin was incubated with mockdepleted (lanes 1,2) or Cdc7-depleted LSS (lanes 3-6) supplemented with buffer (lanes 1-4) or $40 \mathrm{nM}$ rCdc7-Drf1 (lanes 5,6) and isolated at the indicated time points. Chromatin-bound proteins were probed with the indicated antibodies. $\left({ }^{\star}\right)$ Cross-reacting band. (B) The reactions described in $A$ were separately incubated with $\left[\alpha_{-}{ }^{32} \mathrm{P}\right] \mathrm{dATP}$. The replication efficiency was calculated based on incorporation of ${ }^{32} \mathrm{P}$ - $\alpha$-dATP (see the Materials and Merthods) and the results were graphed.

We postulated that Scc2-Scc4 might be codepleted with Cdc7. To test this possibility, we immunoprecipitated Cdc7 from Xenopus egg extracts. Strikingly, Cdc7 IP removed not only $\sim 100 \%$ of Cdc7, Dbf4, and Drf1 from the extract, but also the majority of Scc2 and Scc4 (Fig. 3A, lane 2). Like Cdc7, Drf1, and Dbf4, Scc2 and Scc4 were recovered in the IP fraction (Fig. 3A, lane 6). The data indicate that DDK interacts efficiently with Scc2-Scc4.

We next asked whether Cdc7-Drf1, Cdc7-Dbf4, or both DDK complexes associate with Scc2-Scc4. In Xenopus egg extracts, Drf1 is $\sim 20$-fold more abundant than Dbf4 (Takahashi and Walter 2005). Thus, $\sim 70 \%-80 \%$ of Cdc7 associates with Drf1, $4 \%$ associates with Dbf4, and $\sim 20 \%-30 \%$ is free of known regulatory subunits. Cdc7-Drf1 and Cdc7-Dbf4 were immunoprecipitated separately using antibodies against Drf1 or Dbf4, respectively. Scc2-Scc4 was coprecipitated with both Dbf4 and Drf1, but much more Scc2-Scc4 was recovered with Drf1 than with Dbf4 (Fig. 3A, cf. panels I,II,V, lanes 6-8). Consistent with this observation, Drf1 depletion but not Dbf4 depletion significantly reduced Scc2-Scc4 levels in extract (Fig. 3A, panels I,II, lanes 3,4). We next performed the reciprocal IP. As shown in Figure 3B, Scc2 IP and Scc4 IP each coprecipitated both Drf1 and Dbf4, as well as Cdc7 (Fig. 3B, lanes 4-6). We conclude that both Cdc7-
Drf1 and Cdc7-Dbf4 are associated with Scc2-Scc4. These results suggested that the failure to efficiently rescue Scc2-Scc4 chromatin loading by rCdc7-Drf1 in Cdc7-depleted extracts (Fig. 2A) might be due to codepletion of the majority of Scc2-Scc4 with Cdc7.

Although IP of Cdc7 codepleted $\sim 70 \%$ of Scc2-Scc4 from LSS (Fig. 3A), Scc2-Scc4 IP had only a minor impact on Cdc7, Dbf4, and Drf1 levels in the extract (Fig. 3B, panels III-V, lanes 2,3). This could be explained if DDKs are more abundant than Scc2-Scc4 in egg extracts. Indeed, quantitative Western blotting showed that the concentration of Scc2 in LSS is $\sim 4 \mathrm{nM}$ (data not shown), compared with 20-30 nM Cdc7 (Takahashi and Walter 2005). Therefore, while most of Scc2-Scc4 associates with DDKs, only a subpopulation of DDK binds Scc2Scc4. We speculate that most of the Scc2-Scc4 that remains after Cdc7 depletion is incompetent for binding to DDK and therefore does not support cohesin loading upon readdition of $\mathrm{rCdc} 7-\mathrm{Drf} 1$.

\section{DDK associates with cohesin via Scc2-Scc4}

In the IP experiments described above, we also blotted for $\operatorname{Rad} 21$ and noted that cohesin is part of the complex containing Scc2-Scc4 and DDK. Thus, IP of Cdc7, Dbf4, or Drf1 also precipitated Rad21, and the amount of $\operatorname{Rad} 21$
A

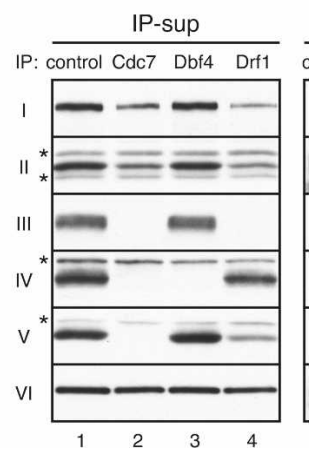

B

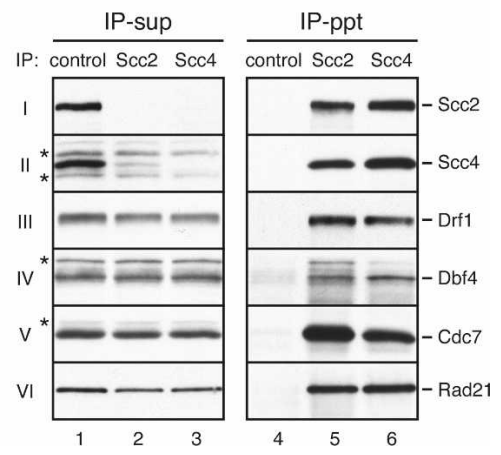

Figure 3. Cdc7-kinase complexes physically associate with Scc2-Scc4. (A) IP was performed with control (lanes 1,5), antiCdc7 (lanes 2,6), anti-Dbf4 (lanes 3,7), or anti-Drf1 antibody (lanes 4,8) from LSS. Supernatants (IP-sup; lanes 1-4) and immunoprecipitates (IP-ppt; lanes 5-8) were probed with the indicated antibodies. $\left({ }^{\star}\right)$ Cross-reacting band. $(B)$ IP was performed with control (lanes 1,4), anti-Scc2 (lanes 2,5), or anti-Scc4 antibody (lanes 3,6) from LSS. Supernatants (IP-sup; lanes 1-3) or immunoprecipitates (IP-ppt; lanes 4-6) were probed with the indicated antibodies. $\left({ }^{\star}\right)$ Cross-reacting band. 
recovered was proportional to the level of Scc2-Scc4 present in the immunoprecipitates (Fig. 3A, panel VI, lanes 6-8). In addition, IP of Scc2 or Scc4 also precipitated Rad21 (Fig. 3B, panel VI, lanes 5,6). Notably, only a fraction of the total Rad21 was coprecipitated with DDK and Scc2-Scc4 (Fig. 3A [lanes 2-4], B [lanes 2,3]), perhaps because cohesin does not bind very tightly to the Scc2Scc4-DDK complex or because cohesin is in excess. We next determined whether the interaction of cohesin and DDK depended on Scc2-Scc4 (Fig. 4). Extracts were mock depleted or depleted of Scc2-Scc4, and then subjected to Cdc7 IP. Strikingly, in the absence of Scc2Scc4, coprecipitation of Rad21 and Smc1 with Cdc7 was severely reduced (Fig. 4, panels VI,VII, lanes 7,8). As we found previously (Takahashi and Walter 2005), Drf1 did not coimmunoprecipitate Dbf4 and vice versa (Fig. 3A, lanes 7,8$)$. Together, these results demonstrate that egg extracts contain a large complex consisting of Scc2-Scc4, cohesin, and either Cdc7-Drf1 or Cdc7-Dbf4, and they indicate that Scc2-Scc4 forms a bridge between DDK and cohesin.

\section{The Cdc7 and Drf1 subunits of DDK are required} for binding to Scc2-Scc4

Our results demonstrate that both DDKs (Cdc7-Drf1 and Cdc7-Dbf4) interact with Scc2-Scc4 (Fig. 3). However, Dbf4 and Drf1 are not well conserved (21\% identical). Therefore, how both DDKs efficiently bind to Scc2-Scc4 was of interest. Since Cdc7 is a shared component of both DDKs, it seemed possible that $\mathrm{Cdc} 7$ alone mediates the interaction of DDKs with Scc2-Scc4. To examine this possibility, we first depleted Dbf4 and Drf1 from LSS, which leaves behind "free" Cdc7 (Fig. 5A, lane 2). Subsequently, Cdc7 was immunoprecipitated and coprecipitation of Scc2-Scc4 was examined. Strikingly, no
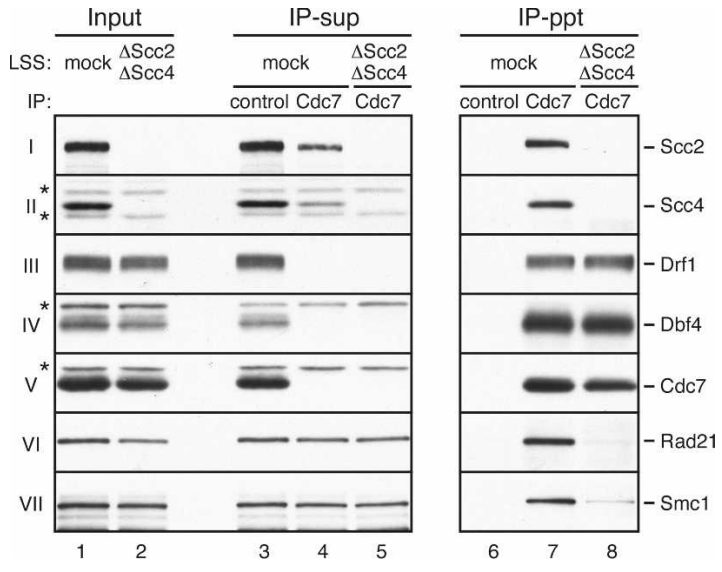

Figure 4. Cdc7 and cohesin associate via Scc2-Scc4. LSS was depleted with either control (lanes $1,3,4,6,7)$ or a mixture of Scc2 and Scc4 antibodies (lanes 2,5,8). IP from the resulting LSS was performed with control (lanes 3,6) or Cdc7 antibody (lanes $4,5,7,8)$. Input (lanes 1,2), supernatants (IP-sup; lanes 3-5), and immunoprecipitates (IP-ppt; lanes 6-8) were probed with the indicated antibodies. $\left({ }^{\star}\right)$ Cross-reacting band.
Scc2 signal above background was detected in the Cdc7 IP (Fig. 5A, lane 10). In contrast, when an equivalent amount of Cdc7 was recovered from LSS that contained Dbf4 and Drf1, Scc2 was readily detected (Fig. 5A, lane 13). This result suggested that $\mathrm{Cdc} 7$ requires a regulatory subunit to bind Scc2-Scc4. To directly test this idea, we added rDrf1 to the Dbf4/Drf1-depleted LSS, and subsequently performed Cdc7 IP. Importantly, Drf1 and Scc2 were now recovered with Cdc7 (Fig. 5A, cf. lanes 10,11), indicating that the "free" Cdc7 is capable of binding to Scc2 if complexed with Drf1. These results show that Cdc7 alone is not able to interact with Scc2-Scc4.

Next, we tested whether Drf1 binds to Scc2-Scc4 by itself. To this end, we added rDrf1 either to a Dbf4/Drf1depleted extract or to a Cdc7-depleted extract, and subsequently performed Drf1 IP. In the former case, rDrf1 associates with "free" Cdc7, while in the latter case, no Cdc7 is available for association. As expected from Figure 5A, rDrf1 IP recovered Scc2 when "free" Cdc7 was present (in a Dbf4/Drf1-depleted extract) (Fig. 5B, lane 15). On the other hand, in the absence of "free" Cdc7 (in a Cdc7-depleted extract), rDrf1 precipitated only a small quantity of Scc2 (Fig. 5B, lane 17). Controls showed that the exogenously added rDrf1 was completely recovered by anti-Drf1 IP, regardless of whether "free" Cdc7 was present (Fig. 5B, lanes 9,11). Moreover, all of the "free" Cdc7 was coprecipitated with rDrf1, showing that all the "free" Cdc7 is capable of binding to rDrf1 (Fig. 5B, lanes $8,9)$. Thus, rDrf1 that is in complex with Cdc7 binds much more efficiently to Scc2-Scc4 than Drf1 alone. In summary, these experiments demonstrate that the association between Cdc7 and Drf1 is essential for efficient Cdc7-Drf1 binding to Scc2-Scc4. We could not perform similar experiments for Cdc7-Dbf4, because we failed to produce soluble Dbf4. However, based on our finding that endogenous Cdc7-Dbf4 binds to Scc2-Scc4, whereas endogenous "free" Cdc7 does not, we propose that the situation is analogous to that of Cdc7-Drf1.

\section{The kinase activity of DDK is essential for chromatin association of Scc2-Scc4}

We showed above that Cdc7 depletion from LSS inhibits chromatin binding of Scc2-Scc4, but rescue of this defect using rCdc7-Drf1 was partial at best, likely because Scc2-Scc4 was codepleted from LSS. Therefore, to prove a role for DDK in Scc2-Scc4 loading, we attempted to reconstitute Cdc7-depleted extracts with rCdc7-Drf1 and rScc2-Scc4. However, despite extensive efforts, we failed to produce significant quantities of full-length recombinant Scc2 ( $330 \mathrm{kDa}, 2950$ amino acids). Instead, we used IVT-expressed Scc2N-Scc4 (Fig. 1D). When added to HSS, the Scc2N-Scc4 complex bound to chromatin in a Cdt1-dependent manner, indicating that it was recruited to chromatin via a mechanism similar to that of the endogenous Scc2-Scc4 complex (Fig. 6A). To test the role of DDK in Scc2-Scc4 loading, extracts were depleted of $\mathrm{Cdc} 7$ and then reconstituted with Scc2N-Scc4 alone or Scc2N-Scc4 and rCde7-Drf1. Strikingly, Scc2N-Scc4 bound to chromatin only in the presence of rCdc7-Drf1 
A

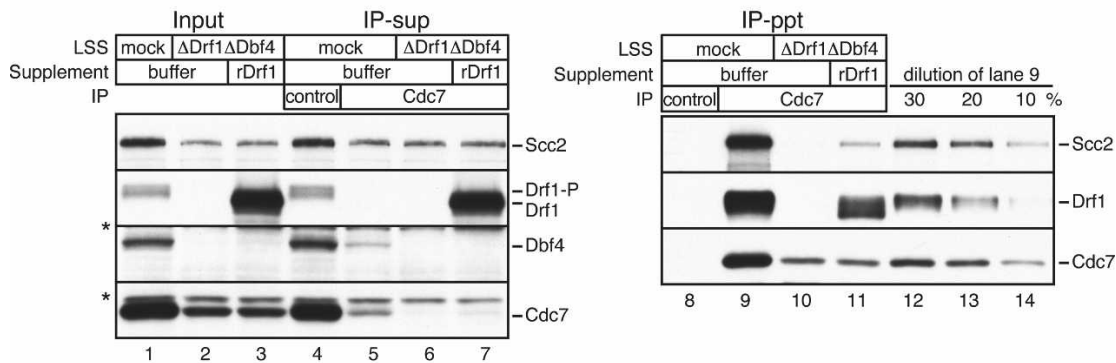

B
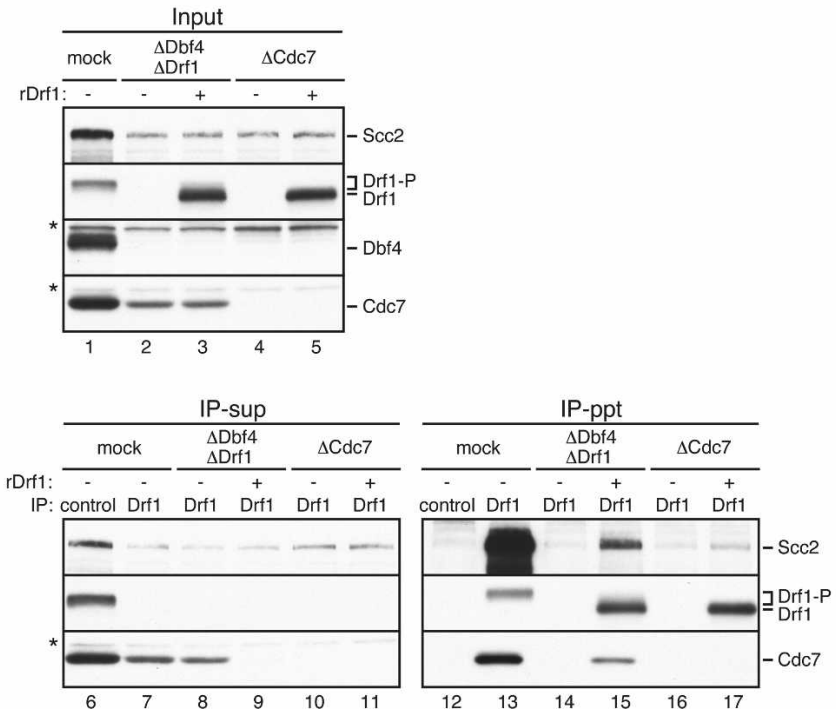

Figure 5. The Cdc7-kinase complex, but not free Cdc7, associates with Scc2. (A) LSS was depleted with either control (lanes $1,4,5,8,9)$ or a mixture of Drf1 and Dbf4 antibodies (lanes 2,3,6,7,10,11), and then supplemented with either buffer (lanes 1,2,4-6,8-10), or recombinant Drf1 (100 nM final concentration; lanes $3,7,11)$. IP from the resulting LSS extracts was performed with control (lanes 4,8) or Cdc7 antibody (lanes 5-7,9-11). Input (lanes 1-3), supernatants (IP-sup; lanes 4-7), immunoprecipitates (IP-ppt; lanes 8-11), and a serial dilution of the sample in lane 9 were probed with the indicated antibodies. $\left({ }^{\star}\right)$ Cross-reacting band. (B) LSS was depleted with control antibody (lanes 1,6,7,12,13), a mixture of Drf1 and Dbf4 antibodies (lanes $2,3,8,9,14,15$ ), or Cdc7-antibody (lanes $4,5,10,11,16,17)$, and then supplemented with either buffer (lanes 1,2,4,6-8,10,12$14,16)$ or $20 \mathrm{nM}$ rDrf1 (lanes $3,5,9,11,15,17)$. IP from the resulting LSS was performed with control (lanes 6,12) or anti-Drf1 antibody (lanes 7-11,13-17). Input (lanes 1-5), supernatants (IP-sup; lanes 6-11), and immunoprecipitates (IP-ppt; lanes 12-17) were probed with the indicated antibodies. $\left({ }^{\star}\right)$ Cross-reacting band.
(Fig. 6B, cf. lanes 3 and 4). Notably, addition of Scc2NScc4 and Cdc7-Drf1 to a Cdc7-depleted HSS did not rescue chromatin association of Rad21 (Fig. 6B lanes 3,4). This result suggests that the C-terminal conserved domain of Scc2 (see Supplemental Fig. S4) is required for loading of cohesin onto chromatin. Similar results were observed using a complex of human Scc2(1-1101)-Scc4 (hScc2N-hScc4) expressed in insect cells (data not shown).

We next addressed whether the protein kinase activity of DDK was required for Scc2-Scc4 recruitment. HSS was depleted of Cdc7 and then reconstituted with wildtype rCdc7-Drf1 or a point mutant, $\mathrm{rCdc} 7^{\mathrm{K} 59 \mathrm{E}}$-Drf1 that is catalytically inactive (Masai et al. 2000). As shown in Figure 6C, only wild-type DDK promoted chromatin association of Scc2N-Scc4 above background levels, indicating that the kinase activity is essential for Scc2-Scc4 loading (cf. lanes 4 and 5). Both wild-type and mutant rCdc7-Drf1 bound chromatin at similar levels (Fig. 6C, lanes 4,5), demonstrating that the kinase activity of Cdc7Drf1 is not required for its chromatin association. The mutant rCdc7-Drf1 is clearly inactive, as it does not support the characteristic mobility shift in Drf1 (Fig. 6C, lane 6), which reflects autophosphorylation (see Supplemental Fig. S7 in Takahashi and Walter 2005). Collectively, our results demonstrate that in Xenopus egg extracts, an Scc2-Scc4-cohesin complex is recruited to pre-RCs via a mechanism that involves the protein kinase activity of DDK.

\section{Discussion}

Cohesin is loaded onto chromatin in the G1 phase so that functional sister chromatid cohesion may be established in S phase (Uhlmann and Nasmyth 1998; Lengronne et al. 2006). In all eukaryotic cells, Scc2-Scc4 is essential to recruit cohesin to chromosomes in late mitosis/early $\mathrm{G}_{1}$ and its activity depends on its ability to bind chromatin. However, little is known about how Scc2-Scc4 binds chromatin in any system. Our previous work showed that in Xenopus egg extracts, the chromatin association of Scc2 and cohesin is dependent on the prior establishment of pre-RCs/Gillespie and Hirano 2004; Takahashi et al. 2004). In this study, we characterize the Xenopus Scc2-Scc4 complex and show that it is recruited to pre-RCs by the DDK protein kinase.

Human and Xenopus Scc 4 were identified recently and shown to interact with the Scc2 protein (Bernard et al. 2006; Seitan et al. 2006; Watrin et al. 2006). We independently isolated a cDNA for human and Xenopus Scc4 and performed a detailed analysis of the protein. In agreement with previous two-hybrid experiments (Seitan et al. 2006), both human and Xenopus Scc2 and Scc4 inter- 
Figure 6. Binding of Scc2N-Scc 4 complex to chromatin requires the pre-RC and DDK. (A) HSS was depleted with control antibody (lane 1) or Cdt1 antibody (lane 2), and then supplemented with Scc2N and Scc4 expressed in IVT lysates. Sperm chromatin was incubated in the HSS, and after 30 min chromatin-bound proteins were isolated and probed with the indicated antibodies. (B) HSS was depleted with control antibody (lanes 1,2) or Cdc7 antibody (lanes 3,4), and then supplemented with Scc2 and Scc4-expressed IVT lysates (lanes 1-4), buffer (lanes 1,3), or $50 \mathrm{nM}$ of rCdc7Drf1 (His-Strep purified, lanes 2,4). Sperm chromatin was incubated in the HSS and isolated at $30 \mathrm{~min}$. Chromatin-bound proteins were probed with the indicated antibodies. $(C)$ HSS was depleted with control antibody (lanes 1,2) or Cdc7 antibody (lanes 3-5), and then supplemented with unprogrammed IVT lysate (lane 1), or Scc2 and Scc4-expressed IVT lysates (lanes 2-5), buffer (lanes 1-3), $180 \mathrm{nM}$ of wild-type rCdc7-Drf1 (WT; His-Flag-purified, lane 4), or $180 \mathrm{nM}$ of catalytically inactive rCdc $7^{\mathrm{K} 59 \mathrm{E}}-\mathrm{Drf1} \quad(\mathrm{KE}$; His-Flag-purified, lane 5). Sperm chromatin was incubated in the HSS and isolated at $30 \mathrm{~min}$. Chromatinbound proteins were probed with the indicated antibodies. (D) A model for the chromatin loading mechanism of Scc2-Scc4 and cohesin. DDK physically associates with Scc2-Scc4, which in turn binds cohesin. The DDK component of this ternary complex docks onto Mcm2-7 and brings Scc2-Scc4 and cohesin close to the chromatin, thereby allowing cohesin deposition on DNA.

act with each other through their $\mathrm{N}$-terminal domains in coimmunoprecipitation experiments (Supplemental Fig. S3; data not shown). In Xenopus egg extracts, the vast majority of Scc2 and Scc4 reside in a complex with each other (Fig. 1A). Neither subunit is able to load onto chromatin by itself, implying that chromatin loading activity results from complex formation (Fig. 1D). As seen for Scc2 depletion (Takahashi et al. 2004), Scc4 depletion severely reduced chromatin association of cohesin (Fig. 1C). All Scc2 orthologs contain multiple conserved HEAT repeats within their $\mathrm{C}$ termini (Neuwald and Hirano 2000), but the vertebrate orthologs have an $\mathrm{N}$-terminal extension that is absent in yeast (Supplemental Fig. S4). Importantly, this $\mathrm{N}$ terminus, in complex with Scc4, is able to load onto chromatin, but does not support cohesin recruitment. Based on these results, we propose that the C-terminal HEAT repeat-containing domain performs the conserved cohesin loading function, whereas the $\mathrm{N}$ terminus evolved to cooperate with Scc4 to form a vertebrate-specific chromatin loading module. Since both Mcm2-7 and DDK binding to chromatin is lost during the course of S phase (Chong et al. 1995; Kubota et al. 1995; Jares and Blow 2000; Walter 2000), whereas Scc2-Scc4 binding persists (Gillespie and Hirano 2004; Takahashi et al. 2004), we speculate that after its initial recruitment, prolonged association of Scc2Scc4 with chromatin involves an unknown mechanism that is Mcm2-7 and DDK independent.

We previously showed that Scc2 (and now Scc4) becomes stably associated with chromatin in a pre-RC-dependent but Cdk2-independent fashion (Gillespie and
Hirano 2004; Takahashi et al. 2004). The same is true for DDK (Jares and Blow 2000; Walter 2000; Jares et al. 2004; Takahashi and Walter 2005). Here, we establish that DDK and Scc2-Scc4 bind tightly to one another in Xenopus egg extracts and that DDK depletion abolishes binding of endogenous Scc2-Scc4 to chromatin (Fig. 2). Although this defect could not be efficiently rescued with DDK, we were able to rescue chromatin loading of recombinant Scc2N-Scc4 with rCdc7-Drf1 in DDK-depleted extracts. Together, the data argue that Cdc7-Drf1 is crucial for chromatin association of endogenous Scc2-Scc4 and cohesin in Xenopus egg extracts. Interestingly, in fission yeast, Cdc7 is involved in chromatin association of cohesin at pericentromeric loci, likely via a pre-RCindependent mechanism (Takeda et al. 2001; Bailis et al. 2003), suggesting evolutionally conserved benefits to link DDK to cohesin loading.

How does DDK promote pre-RC-dependent Scc2-Scc4 chromatin loading? DDK interacts stably with pre-RCs (Takahashi and Walter 2005; Silva et al. 2006) and with Scc2-Scc4 (this study), suggesting that DDK plays a structural role in Scc2-Scc4 recruitment. Importantly, we also showed that the protein kinase activity of DDK is required to promote Scc2-Scc4 loading onto chromatin. In this reaction, Scc2-Scc4 itself may be the relevant substrate of DDK. In this scenario, the phosphorylation of Scc2-Scc4 might be required to generate the tight complex of Scc2-Scc4 with DDK or to mediate binding to the pre-RC. Phosphorylation-dependent interaction between a kinase and its substrate has been observed for Cdk, a rCdc7-Drf1, possibly due to codepletion of Scc2-Scc4 with 
protein kinase related to DDK (Mimura et al. 2004). Alternatively, the relevant substrate of DDK may be Mcm2-7, whose phosphorylation may generate a suitable docking site for Scc2-Scc4. Finally, DDK may phosphorylate unknown substrates to promote Scc2-Scc4 chromatin loading. These questions will be addressed in the future.

It is important to consider whether pre-RC-dependent and DDK-dependent Scc2-Scc4 loading might occur in other organisms. In $S$. cerevisiae, pre-RC formation is not required for cohesin recruitment (Uhlmann and Nasmyth 1998), and Cdc7 is dispensable in some genetic backgrounds (Hardy et al. 1997), even though cohesion is essential for viability. These observations suggest that the pre-RC/DDK cohesin loading pathway is not active in this organism. In mammalian tissue culture cells, vertebrate Scc2, Scc4, and cohesin associate with chromatin in telophase (Darwiche et al. 1999; Sumara et al. 2000; Waizenegger et al. 2000; Watrin et al. 2006), at the same time when pre-RCs are assembled on chromatin (Mendez and Stillman 2000). In addition, siRNA depletion of human Drf1 causes defects in M-phase progression (Yoshizawa-Sugata et al. 2005). These observations are consistent with the notion that pre-RCs and DDK both participate in cohesin loading in mammalian cells. While Dbf4 protein levels peak in S phase, Drf1 levels are highest at G2/M, consistent with a possible role in cohesin recruitment in telophase (Jiang et al. 1999; Kumagai et al. 1999; Montagnoli et al. 2002). In Drosophila cells, genome-wide mapping of cohesin and Scc2 localization showed that both factors preferentially localize to transcriptionally active sites that overlap with RNA polymerase II (Misulovin et al. 2008). Interestingly, earlier experiments showed that replication origins in Drosophila cells also correlate with transcriptionally active sites, and a subset of ORC binding sites colocalizes with RNA polymerase II (MacAlpine et al. 2004). Thus, there might be a correlation between replication origins and Scc2 localization.

What are the potential benefits of using DDK and Mcm2-7 to promote cohesin recruitment? First, coupling Scc2-Scc4 loading to DDK and Mcm2-7 enables loading of cohesin onto chromatin prior to the initiation of DNA replication. As a result, cohesin is available on chromatin when cohesion is established in S phase. Second, in all eukaryotic cells, origins of replication are distributed at regular intervals on the chromatin. Therefore, using DDK and Mcm2-7 for cohesin loading provides a convenient means to achieve a regular distribution of cohesin-binding sites. In this senario, not all pre-RCs might serve as cohesin loading sites, since only a subpopulation of DDK binds to Scc2-Scc4 (Fig. 3). In good agreement with this view, the average intercohesin distance in this system is $20 \mathrm{~kb}$ (Losada et al. 1998), which is greater than average interorigin distance of $7-10 \mathrm{~kb}$ (Hyrien and Mechali 1993). Why is Mcm2-7 alone not used to recruit Scc2-Scc4 and cohesin to pre-RCs? We speculate that direct binding of Scc2-Scc4 and cohesin to Mcm2-7 might be inhibitory for DNA replication, since Mcm2-7 activation and helicase activity requires interactions with nu- merous proteins. In this view, binding of Scc2-Scc4 to DDK allows the use of Mcm2-7 as a platform for cohesin assembly without causing steric inhibition of replication. In conclusion, our results establish the first outlines of a molecular pathway for Scc2-Scc4 chromatin loading in any organism, and future experiments will be required to elucidate the underlying mechanisms.

\section{Materials and methods}

\section{Cloning}

To clone the human Scc4 gene, a BLAST search using Schizosaccharomyces pombe Ss13 (NP_593137), an ortholog of S. cereviseae Scc4 (Bernard et al. 2006), identified a human gene, KIAA0892. Based on the KIAA0892 sequence, two primers, (forward with BamHI site) 5'-CGCGGATCCACCATGCGGCTT GTTGTTGTG-3' and (reverse with Xhol site) 5'-CCGCTC GAGTCACAGGAGGCTGGCCAGGC-3', were used to amplify the human Scc4 gene from Human HeLa Marathon Ready cDNA (Clontech) by using Accuprime $P f_{X}$ Supermix (Invitrogen). The amplified hScc4 was double digested with BamHI and XhoI and then ligated into BamHI/XhoI-digested pET28a (Novagen). The recombinant pET28a-hScc4 was sequenced and compared with human KIAA0892. No error was identified during the amplification and cloning.

Cloning of Xenopus SCC4 (XSCC4) gene was performed as follows: A BLAST search (http://compbio.dfci.harvard.edu/tgi/ cgi-bin/tgi/gimain.pl?gudb=xenopus) using the human Scc4 sequence identified two Xenopus EST clones, TC260044 and TC290672, which contain N-terminal and C-terminal regions of the Xenopus Scc4 homolog, respectively. Based on these ESTs, we used two primers, 5'-AAAGCAGGCTCCACCCATATGT CAGTGATGGCGGCTACGGCG-3' and 5'-TTTCGAACTGC GGGT GGCTCCAGGATCCCAAAAGGCTGGCCAAGCTG GTGGTGGG-3', to amplify the XSCC4 gene (1821 nucleotides) via PCR from Xenopus egg cDNA (a kind gift from Eunah Chung and Joan Ruderman). The Gateway cloning sequences (Invitrogen) and a C-terminal Strep-II tag (IBA) were added in a second round of PCR using the amplified XSCC4 DNA fragment and primers 5'-GGGGACAAGTTTGTACAAAAAAG CAGGCTCCAC-3' and 5'-GGGGACCACTTTGTACAAGAA AGCTGGGTTTATTTTT CGAACTGCGGGTGGCTCC-3'. The resulting DNA fragment was cloned into pDONR201 vector (Invitrogen) by the Gateway BP reaction. To construct XSCC4 fragments corresponding to amino acid residues 1-205, 201-410, and 404-607, PCR was performed using primes $5^{\prime}$-AA AAAACCATGGGATCAGTGATGGCGGCTACG-3' and 5'-A AAAGGATCCTCACAAGGTGAGAAGCGGATGCAC-3', $5^{\prime}$ A AA ACC AT GGGACCGC TTCTCA CCTT GTGT GG-3' and 5'-AAAAGGATCCTCACCACAGCTCCTGGTGCGTTGTTA GC-3', and 5'-AAAACCATGGGAACAACGCACCAGGAGC TGTGG-3', and 5'-AAAAGGATCCTCACAAAAGGCTGGCC AAGCTGG-3', respectively. Using XSCC2 sequence information kindly provided by Koichi Tanaka, Kim Nasmyth, and JanMichael Peters, XSCC2 fragments corresponding to amino acid residues 1-485, 447-1040, and 1015-1489 were amplified by PCR from a Xenopus cDNA library (a kind gift from Vladimir Joukov) using 5'-AAAGCAGGCTCCACCCTCGAGATGAAT GGGGATATGCCTCATGTTCCC-3' and 5'-ACAAGAAAGC TGGG TCTCCT GCAGGTCCACTA GGCATGCTTCTAGAC CGCTCGATAGCGGACTCC-3'， 5'-AAAGCAGGCTCCACC ATGCCTCTTGTGGCTCAGTCACAGC-3' and 5'-ACAAG AAAGCTGGGTCCCTGGGACTACCAGGCCTTGG-3' and 5'-AAAGCAGGCTCCACCATGAAGCATCGGCATGATTC 
GG-3' and 5' $^{\prime}$-ACAAGAAAGCTGGGTCTGCATGCTTAAC GTGCTCAATCACATCCTCG-3', respectively. The Gateway cloning sequences were then added to all the fragments by second-round PCR using primers 5'-GGGGACAAGTTTGTA CAAAAAAGCAGGCTCCAC-3' and 5'-GGGGACCACTTTG TACAAGAAAGCTGGGTC-3', and the amplified fragments were cloned into pDONR201 vector by the Gateway $\mathrm{BP}$ reaction, resulting in pDONR-XSCC2(1-485), pDONR-XSCC2(447-1040), and pDONR-XSCC2(1015-1489), respectively. To construct XSCC2 1-1024 fragment, the 1.7-kb NdeI-XbaI fragment from pDONR-XSCC2(447-1040) was cloned into the same sites in pDONR-XSCC2(1-485).

Construction of expression plasmids for wild-type and catalytically inactive mutant (K59E) of Cdc7-Drf1 was performed as follows: Fragments of $X C D C 7$ gene containing the mutation were independently PCR amplified using primer pairs 5'-GGG GACAAG TTTGT ACAAAAAAGCAGGC TT ACATATGAGT TCGGGCGATAATTCAGG-3' and 5'-GGAACTCGAGAGCA AACTTTGCATCTTCTCC-3', and 5'-GGAACTCGAGCATT TAATCCCCACAAGTCACC $-3^{\prime}$ and $5^{\prime}$-GGGGACCACTTTG TACA AGAAAGCTGGG TGGA TCCC TACCGCATGTTTTT AAACAGAGG-3', digested with XhoI, ligated, and cloned into pDONR201 vector by the Gateway BP reaction, resulting in pDONR-XCDC7-K59E. Next, 1.5-kb NdeI-BamHI fragments of wild-type XCDC7 gene (Takahashi and Walter 2005) and the K59E mutant XCDC7 gene were cloned into pETDuet-1 vector (EMD Novagen) at NdeI and BglII sites, resulting in pETD$X C D C 7$ and pETD-XCDC7K59E. His and Flag-StrepII-tagged $X D R F 1$ gene was PCR-amplified using primers 5'-GGAACAT ATGTCCATGGGCCACCACCACCATCACCAT AGT GCTC AGCAGGACGATGAACC-3' and 5'-CGTCGTCCTTGTAGT CGGGCCCCT GGAACAGAACTT CCAGACTTCCCTCGAG TGGATCATGGGTCAGAATGTTGC-3' ${ }^{\prime}$, then using $5^{\prime}$-GGAA CATATGTCCATGGGCCACCACCACCATCACCATAGTG CTCAGCAGGACGATGAACC-3' and 5'-GGAAAGATCTCC TGCAGGTTATTTTTCGAACTGCGGGT GGCTCCACTTG TCATCGTCGTCCTTGTAGTCGGGCCCCTGG-3', digested with NcoI and BglII, and cloned into NcoI and BamHI sites in pETD- $X C D C 7$ and $\mathrm{pETD}-X C D C 7 \mathrm{~K} 59 \mathrm{E}$, respectively, resulting in pETD-His $X D R F 1 F S-X C D C 7$ and pETD-His $X D R F 1 F S-$ $X C D C 7 \mathrm{~K} 59 \mathrm{E}$. The sequences were confirmed after all PCR steps.

\section{Protein expression and in vitro pull-down assay}

For protein expression in Escherichia coli, the XSCC2 or XSCC4 genes were transferred to pDEST17 vector (Invitrogen) by the Gateway LR reaction. Protein expression was induced by addition of $0.1 \mathrm{mM}$ Isopropyl $\beta$-D-1-thiogalactopyranoside (IPTG) to media. Purification of His-tagged proteins was performed following the manufacturer's protocol. Purification of HisStrepII-tagged Cdc7-Drf1 and Drf1 was described previously (Takahashi and Walter 2005). Purification of His-Flag-StrepIItagged wild-type and K59E mutant Cdc7-Drf1 was performed as follows: Protein expression was induced in the E. coli BL21(DE3) strain carrying pETD-His XDRF1FS-XCDC7 or pETDHis $X D R F 1 \mathrm{FS}-X C D C 7 \mathrm{~K} 59 \mathrm{E}$ by $0.1 \mathrm{mM}$ IPTG for $20 \mathrm{~h}$ at $20^{\circ} \mathrm{C}$. The wild-type and K59E mutant Cdc7-HisDrf1Flag-StrepII proteins were purified with His tag, and then Flag tag following the manufacturer's protocol. Proteins were eluted by $100 \mu \mathrm{g} / \mathrm{mL}$ Flag-peptide from Flag-M2 agarose (Sigma Aldrich) in $20 \mathrm{mM}$ Tris- $\mathrm{HCl}$ (pH 7.4), $100 \mathrm{mM} \mathrm{NaCl}, 5 \mathrm{mM}$ 2-mercaptoethanol, 1 mM EDTA in the presence of $10 \mathrm{U} / \mathrm{mL}$ PreScission protease /GE Healthcare). The PreScission protease was then removed by Glutathione-sepharose. For protein expression in in vitro transcription-coupled translation (IVT) system in rabbit reticulocyte lysate, the XSCC2 or XSCC4 genes were transferred to
pCITE4a vector (S tag) (EMD Novagen) using NcoI and BamHI sites, or transferred to pANT7_cGST vector (GST tag) (Ramachandran et al. 2004) (http://plasmid.med.harvard.edu/PLASMID) by the Gateway LR reaction. Proteins were expressed using TNT T7 Coupled Reticulocyte Lysate System (Promega) following the manufacturer's protocol. For in vitro pull-down assay, 8 $\mu \mathrm{L}$ each of IVT-lysate were mixed and incubated for $30 \mathrm{~min}$ at room temperature. Then, $64 \mu \mathrm{L}$ of ELB $(10 \mathrm{mM}$ HEPES-KOH at $\mathrm{pH} 7.7,50 \mathrm{mM} \mathrm{KCl}, 2.5 \mathrm{mM} \mathrm{MgCl}_{2}, 250 \mathrm{mM}$ sucrose) and $5 \mu \mathrm{L}$ of S-protein agarose (EMD Novagen) were added to the lysate, and the mixture was incubated for $1 \mathrm{~h}$ at $4^{\circ} \mathrm{C}$. S-protein agarose was recovered, washed with ELB containing $0.1 \%$ Triton X-100, and bound proteins were eluted with $20 \mu \mathrm{L}$ of Laemmli's SDSPAGE sample buffer.

\section{Extracts, DNA replication, and chromatin binding}

Extract preparation and chromatin-binding assays in the nucleus-free replication system were carried out as described (Walter et al. 1998; Walter and Newport 2000). Sperm nuclei were incubated in HSS at 10,000 per microliter in all experiments. In LSS (Blow 1993), sperm nuclei were incubated at 3000 per microliter in all experiments, and chromatin isolation and replication were carried out as described previously (Takahashi et al. 2004). The amount of DNA synthesis was calculated using the method described by Blow and Laskey (1986). Endogenous dNTP concentration was measured for each extract.

\section{Immunological methods}

Rabbit Scc4 antibodies were raised against N-terminally Histagged and C-terminally Strep-II-tagged full-length Xenopus Scc4 (607 amino acids) expressed in E. coli. Rabbit Scc2 antibodies were raised against a mixture of $\mathrm{N}$-terminally His-tagged Xenopus Scc2 fragments corresponding to residues 447-1040 and 1015-1489, respectively, both expressed in E. coli. Rabbit Rad21 antibodies were raised against peptide TQREPYSDIVATPGPRFHTV, corresponding to residues 610-629 of Xenopus Rad21. Anti-Mcm4 antiserum was a gift from John Newport. Antibodies to Mcm7 (Walter and Newport 2000), Orc2 (Walter and Newport 1997), Cdc7, Dbf4, and Drf1 (Takahashi and Walter 2005) were described previously. All antibodies except for Mcm4, Mcm7, and Orc2 were affinity purified. For Western blotting, all antibodies were used at 1:5,000 dilutions, or for purified antibody, $0.2 \mu \mathrm{g} / \mathrm{mL}$. For depletion of LSS, $3 \mathrm{vol}$ of antiserum were bound to $1 \mathrm{vol}$ of recombinant protein A-sepharose FF ("PAS," GE Healthcare). For Drf1/Dbf4 double depletion, 0.5 vol of anti-Drf1 and 2.5 vol of anti-Dbf4 serum were sequentially bound to 1 vol of PAS. For Scc2/Scc4 double depletion, 1.5 vol each of anti-Scc2 and antiScc4 serum were bound to 1 vol of PAS. To deplete LSS or HSS, 0.2 vol of the above-described PAS beads were incubated with 1 vol of the extract for $2 \mathrm{~h}$ at $4^{\circ} \mathrm{C}$, and the procedure was repeated once. For IPs, $10 \mu \mathrm{g}$ of affinity-purified antibody coupled to 10 $\mu \mathrm{L}$ of PAS were mixed with $50 \mu \mathrm{L}$ of LSS and incubated for $4 \mathrm{~h}$. Beads were isolated and washed with ELB containing $0.1 \%$ Triton $\mathrm{X}-100$ five times.

\section{Accession number}

cDNA sequence of Xenopus SCC4 has been deposited in the GenBank/EMBL/DDBJ under accession number EU747648.

\section{Acknowledgments}

We thank Koichi Tanaka, Kim Nasmyth, and Jan-Michael Peters for human Scc2 sequence information; Eunah Chung, Joan Ruderman, and Vladimir Joukov for Xenopus cDNA libraries; Niroshan Ramachandran and Joshua LaBaer for pANT7_cGST; 
Gernot Walter and Courtney Havens for critical reading of the manuscript; and Emily Arias for insightful discussions. T.S.T. also acknowledges extensive assistance from Hisao Masukata and Takuro Nakagawa in Osaka. T.S.T. was supported by a post-doctoral fellowship for research abroad from the Japan Society for the Promotion of Science (2004), and by a Charles A. King Trust Postdoctoral Fellowship (2006) supported by the Charles A. King Trust, Bank of America, Co-Trustee. This work was supported by NIH grants GM62267 (J.C.W.), GM034559 (J.H.), GM077440 (J.H.), and a Leukemia and Lymphoma Scholar Award (J.C.W.).

\section{References}

Bailis, J.M., Bernard, P., Antonelli, R., Allshire, R.C., and Forsburg, S.L. 2003. Hsk1-Dfp1 is required for heterochromatinmediated cohesion at centromeres. Nat. Cell Biol. 5: 11111116.

Bell, S.P. and Dutta, A. 2002. DNA replication in eukaryotic cells. Annu. Rev. Biochem. 71: 333-374.

Bermudez, V.P., Maniwa, Y., Tappin, I., Ozato, K., Yokomori, K., and Hurwitz, J. 2003. The alternative Ctf18-Dcc1-Ctf8replication factor $\mathrm{C}$ complex required for sister chromatid cohesion loads proliferating cell nuclear antigen onto DNA. Proc. Nat1. Acad. Sci. 100: 10237-10242.

Bernard, P., Drogat, J., Maure, J.F., Dheur, S., Vaur, S., Genier, S., and Javerzat, J.P. 2006. A screen for cohesion mutants uncovers Ssl3, the fission yeast counterpart of the cohesin loading factor Scc4. Curr. Biol. 16: 875-881.

Blow, J.J. 1993. Preventing re-replication of DNA in a single cell cycle: Evidence for a replication licensing factor. J. Cell Biol. 122: 993-1002.

Blow, J.J. and Laskey, R.A. 1986. Initiation of DNA replication in nuclei and purified DNA by a cell-free extract of Xenopus eggs. Cell 47: 577-587.

Chong, J.P., Mahbubani, H.M., Khoo, C.Y., and Blow, J.J. 1995. Purification of an MCM-containing complex as a component of the DNA replication licensing system. Nature 375: 418-421.

Ciosk, R., Shirayama, M., Shevchenko, A., Tanaka, T., Toth, A., and Nasmyth, K. 2000. Cohesin's binding to chromosomes depends on a separate complex consisting of Scc2 and Scc4 proteins. Mol. Cell 5: 243-254.

Darwiche, N., Freeman, L.A., and Strunnikov, A. 1999. Characterization of the components of the putative mammalian sister chromatid cohesion complex. Gene 233: 39-47.

Furuya, K., Takahashi, K., and Yanagida, M. 1998. Faithful anaphase is ensured by Mis4, a sister chromatid cohesion molecule required in $S$ phase and not destroyed in G1 phase. Genes \& Dev. 12: 3408-3418.

Gambus, A., Jones, R.C., Sanchez-Diaz, A., Kanemaki, M., van Deursen, F., Edmondson, R.D., and Labib, K. 2006. GINS maintains association of Cdc45 with MCM in replisome progression complexes at eukaryotic DNA replication forks. Nat. Cell Biol. 8: 358-366.

Gillespie, P.J. and Hirano, T. 2004. Scc2 couples replication licensing to sister chromatid cohesion in Xenopus egg extracts. Curr. Biol. 14: 1598-1603.

Hanna, J.S., Kroll, E.S., Lundblad, V., and Spencer, F.A. 2001. Saccharomyces cerevisiae CTF18 and CTF4 are required for sister chromatid cohesion. Mol. Cell. Biol. 21: 3144-3158.

Hardy, C.F., Dryga, O., Seematter, S., Pahl, P.M., and Sclafani, R.A. 1997. mcm5/cdc46-bob1 bypasses the requirement for the S phase activator Cdc7p. Proc. Natl. Acad. Sci. 94: 31513155.

Hauf, S., Roitinger, E., Koch, B., Dittrich, C.M., Mechtler, K., and Peters, J.M. 2005. Dissociation of cohesin from chromo- some arms and loss of arm cohesion during early mitosis depends on phosphorylation of SA2. PLoS Biol. 3: e69. doi: 10.1371/journal.pbio.0030069.

Hirano, T. 2006. At the heart of the chromosome: SMC proteins in action. Nat. Rev. Mol. Cell Biol. 7: 311-322.

Huang, C.E., Milutinovich, M., and Koshland, D. 2005. Rings, bracelet or snaps: Fashionable alternatives for Smc complexes. Philos. Trans. R. Soc. Lond. B Biol. Sci. 360: 537-542.

Hyrien, O. and Mechali, M. 1993. Chromosomal replication initiates and terminates at random sequences but at regular intervals in the ribosomal DNA of Xenopus early embryos. EMBO J. 12: 4511-4520.

Ivanov, D. and Nasmyth, K. 2005. A topological interaction between cohesin rings and a circular minichromosome. Cell 122: 849-860.

Ivanov, D. and Nasmyth, K. 2007. A physical assay for sister chromatid cohesion in vitro. Mol. Cell 27: 300-310.

Jackson, A.L., Pahl, P.M., Harrison, K., Rosamond, J., and Sclafani, R.A. 1993. Cell cycle regulation of the yeast Cdc7 protein kinase by association with the Dbf4 protein. Mol. Cell. Biol. 13: 2899-2908.

Jares, P. and Blow, J.J. 2000. Xenopus cdc7 function is dependent on licensing but not on XORC, XCdc6, or CDK activity and is required for XCdc45 loading. Genes \& Dev. 14: 1528-1540.

Jares, P., Luciani, M.G., and Blow, J.J. 2004. A Xenopus Dbf4 homolog is required for Cdc7 chromatin binding and DNA replication. BMC Mol. Biol. 5: 5. doi: 10.1186/1471-2199-5-5.

Jiang, W., McDonald, D., Hope, T.J., and Hunter, T. 1999. Mammalian Cdc7-Dbf4 protein kinase complex is essential for initiation of DNA replication. EMBO I. 18: 5703-5713.

Kenna, M.A. and Skibbens, R.V. 2003. Mechanical link between cohesion establishment and DNA replication: Ctf7p/Ecolp, a cohesion establishment factor, associates with three different replication factor C complexes. Mol. Cell. Biol. 23: 2999-3007.

Krantz, I.D., McCallum, J., DeScipio, C., Kaur, M., Gillis, L.A., Yaeger, D., Jukofsky, L., Wasserman, N., Bottani, A., Morris, C.A., et al. 2004. Cornelia de Lange syndrome is caused by mutations in NIPBL, the human homolog of Drosophila melanogaster Nipped-B. Nat. Genet. 36: 631-635.

Kubota, Y., Mimura, S., Nishimoto, S., Takisawa, H., and Nojima, H. 1995. Identification of the yeast MCM3-related protein as a component of Xenopus DNA replication licensing factor. Cell 81: 601-609.

Kubota, Y., Takase, Y., Komori, Y., Hashimoto, Y., Arata, T., Kamimura, Y., Araki, H., and Takisawa, H. 2003. A novel ring-like complex of Xenopus proteins essential for the initiation of DNA replication. Genes \& Dev. 17: 1141-1152.

Kumagai, H., Sato, N., Yamada, M., Mahony, D., Seghezzi, W., Lees, E., Arai, K., and Masai, H. 1999. A novel growth- and cell cycle-regulated protein, ASK, activates human Cdc7-related kinase and is essential for G1/S transition in mammalian cells. Mol. Cell. Biol. 19: 5083-5095.

Lengronne, A., Katou, Y., Mori, S., Yokobayashi, S., Kelly, G.P., Itoh, T., Watanabe, Y., Shirahige, K., and Uhlmann, F. 2004. Cohesin relocation from sites of chromosomal loading to places of convergent transcription. Nature 430: 573-578.

Lengronne, A., McIntyre, J., Katou, Y., Kanoh, Y., Hopfner, K.P., Shirahige, K., and Uhlmann, F. 2006. Establishment of sister chromatid cohesion at the $S$. cerevisiae replication fork. Mol. Cell 23: 787-799.

Losada, A. 2007. Cohesin regulation: Fashionable ways to wear a ring. Chromosoma 116: 321-329.

Losada, A., Hirano, M., and Hirano, T. 1998. Identification of Xenopus SMC protein complexes required for sister chromatid cohesion. Genes \& Dev. 12: 1986-1997. 
Losada, A., Hirano, M., and Hirano, T. 2002. Cohesin release is required for sister chromatid resolution, but not for condensin-mediated compaction, at the onset of mitosis. Genes \& Dev. 16: 3004-3016.

MacAlpine, D.M., Rodriguez, H.K., and Bell, S.P. 2004. Coordination of replication and transcription along a Drosophila chromosome. Genes \& Dev. 18: 3094-3105.

Masai, H. and Arai, K. 2002. Cdc7 kinase complex: A key regulator in the initiation of DNA replication. J. Cell. Physiol. 190: $287-296$.

Masai, H., Matsui, E., You, Z., Ishimi, Y., Tamai, K., and Arai, K. 2000. Human Cdc7-related kinase complex. In vitro phosphorylation of MCM by concerted actions of Cdks and Cdc7 and that of a criticial threonine residue of Cdc7 by Cdks. J. Biol. Chem. 275: 29042-29052.

Masai, H., Taniyama, C., Ogino, K., Matsui, E., Kakusho, N., Matsumoto, S., Kim, J.M., Ishii, A., Tanaka, T., Kobayashi, T., et al. 2006. Phosphorylation of MCM4 by Cdc7 kinase facilitates its interaction with $\mathrm{Cdc} 45$ on the chromatin. $J$. Biol. Chem. 281: 39249-39261.

Mayer, M.L., Gygi, S.P., Aebersold, R., and Hieter, P. 2001. Identification of RFC(Ctf18p, Ctf8p, Dcclp): An alternative RFC complex required for sister chromatid cohesion in $S$. cerevisiae. Mol. Cell 7: 959-970.

Mendez, J. and Stillman, B. 2000. Chromatin association of human origin recognition complex, cdc6, and minichromosome maintenance proteins during the cell cycle: Assembly of prereplication complexes in late mitosis. Mol. Cell. Biol. 20: 8602-8612.

Miles, J. and Formosa, T. 1992. Evidence that POB1, a Saccharomyces cerevisiae protein that binds to DNA polymerase $\alpha$, acts in DNA metabolism in vivo. Mol. Cell. Biol. 12: 5724 5735 .

Milutinovich, M., Unal, E., Ward, C., Skibbens, R.V., and Koshland, D. 2007. A multi-step pathway for the establishment of sister chromatid cohesion. PLoS Genet. 3: e12. doi: 10.1371/ journal.pgen.0030012.

Mimura, S., Seki, T., Tanaka, S., and Diffley, J.F. 2004. Phosphorylation-dependent binding of mitotic cyclins to Cdc6 contributes to DNA replication control. Nature 431: 11181123.

Misulovin, Z., Schwartz, Y.B., Li, X.Y., Kahn, T.G., Gause, M., Macarthur, S., Fay, J.C., Eisen, M.B., Pirrotta, V., Biggin, M.D., et al. 2008. Association of cohesin and Nipped-B with transcriptionally active regions of the Drosophila melanogaster genome. Chromosoma 117: 89-102.

Moldovan, G.L., Pfander, B., and Jentsch, S. 2006. PCNA controls establishment of sister chromatid cohesion during $\mathrm{S}$ phase. Mol. Cell 23: 723-732

Montagnoli, A., Bosotti, R., Villa, F., Rialland, M., Brotherton, D., Mercurio, C., Berthelsen, J., and Santocanale, C. 2002. Drf1, a novel regulatory subunit for human Cdc7 kinase. EMBO I. 21: 3171-3181.

Montagnoli, A., Valsasina, B., Brotherton, D., Troiani, S., Rainoldi, S., Tenca, P., Molinari, A., and Santocanale, C. 2006. Identification of $\mathrm{Mcm} 2$ phosphorylation sites by S-phaseregulating kinases. J. Biol. Chem. 281: 10281-10290.

Moyer, S.E., Lewis, P.W., and Botchan, M.R. 2006. Isolation of the Cdc45/Mcm2-7/GINS (CMG) complex, a candidate for the eukaryotic DNA replication fork helicase. Proc. Nat1. Acad. Sci. 103: 10236-10241.

Nasmyth, K. and Haering, C.H. 2005. The structure and function of SMC and kleisin complexes. Annu. Rev. Biochem. 74: 595-648.

Neuwald, A.F. and Hirano, T. 2000. HEAT repeats associated with condensins, cohesins, and other complexes involved in chromosome-related functions. Genome Res. 10: 1445-1452.

Pacek, M. and Walter, J.C. 2004. A requirement for MCM7 and Cdc45 in chromosome unwinding during eukaryotic DNA replication. EMBO J. 23: 3667-3676.

Pacek, M., Tutter, A.V., Kubota, Y., Takisawa, H., and Walter, J.C. 2006. Localization of MCM2-7, Cdc45, and GINS to the site of DNA unwinding during eukaryotic DNA replication. Mol. Cell 21: 581-587.

Ramachandran, N., Hainsworth, E., Bhullar, B., Eisenstein, S., Rosen, B., Lau, A.Y., Walter, J.C., and LaBaer, J. 2004. Selfassembling protein microarrays. Science 305: 86-90.

Rollins, R.A., Korom, M., Aulner, N., Martens, A., and Dorsett, D. 2004. Drosophila nipped-B protein supports sister chromatid cohesion and opposes the stromalin/Scc3 cohesion factor to facilitate long-range activation of the cut gene. Mol. Cell. Biol. 24: 3100-3111.

Sclafani, R.A. 2000. Cdc7p-Dbf4p becomes famous in the cell cycle. J. Cell Sci. 113: 2111-2117.

Seitan, V.C., Banks, P., Laval, S., Majid, N.A., Dorsett, D., Rana, A., Smith, J., Bateman, A., Krpic, S., Hostert, A., et al. 2006. Metazoan Scc4 homologs link sister chromatid cohesion to cell and axon migration guidance. PLoS Biol. 4: e242. doi: 10.1371/journal.pbio.0040242.

Sheu, Y.J. and Stillman, B. 2006. Cdc7-Dbf4 phosphorylates MCM proteins via a docking site-mediated mechanism to promote S phase progression. Mol. Cell 24: 101-113.

Silva, T., Bradley, R.H., Gao, Y., and Coue, M. 2006. Xenopus CDC7/DRF1 complex is required for the initiation of DNA replication. J. Biol. Chem. 281: 11569-11576.

Skibbens, R.V., Corson, L.B., Koshland, D., and Hieter, P. 1999. Ctf7p is essential for sister chromatid cohesion and links mitotic chromosome structure to the DNA replication machinery. Genes \& Dev. 13: 307-319.

Sumara, I., Vorlaufer, E., Gieffers, C., Peters, B.H., and Peters, J.M. 2000. Characterization of vertebrate cohesin complexes and their regulation in prophase. J. Cell Biol. 151: 749-762.

Takahashi, T.S. and Walter, J.C. 2005. Cdc7-Drf1 is a developmentally regulated protein kinase required for the initiation of vertebrate DNA replication. Genes \& Dev. 19: 2295-2300.

Takahashi, T.S., Yiu, P., Chou, M.F., Gygi, S., and Walter, J.C. 2004. Recruitment of Xenopus Scc2 and cohesin to chromatin requires the pre-replication complex. Nat. Cell Biol. 6: 991-996.

Takayama, Y., Kamimura, Y., Okawa, M., Muramatsu, S., Sugino, A., and Araki, H. 2003. GINS, a novel multiprotein complex required for chromosomal DNA replication in budding yeast. Genes \& Dev. 17: 1153-1165.

Takeda, T., Ogino, K., Tatebayashi, K., Ikeda, H., Arai, K., and Masai, H. 2001. Regulation of initiation of S phase, replication checkpoint signaling, and maintenance of mitotic chromosome structures during $S$ phase by Hsk1 kinase in the fission yeast. Mol. Biol. Cell 12: 1257-1274.

Tanaka, S., Umemori, T., Hirai, K., Muramatsu, S., Kamimura, Y., and Araki, H. 2007. CDK-dependent phosphorylation of Sld2 and Sld3 initiates DNA replication in budding yeast. Nature 445: 328-332.

Tonkin, E.T., Wang, T.J., Lisgo, S., Bamshad, M.J., and Strachan, T. 2004. NIPBL, encoding a homolog of fungal Scc2-type sister chromatid cohesion proteins and fly Nipped-B, is mutated in Cornelia de Lange syndrome. Nat. Genet. 36: 636-641.

Toth, A., Ciosk, R., Uhlmann, F., Galova, M., Schleiffer, A., and Nasmyth, K. 1999. Yeast cohesin complex requires a conserved protein, Ecolp(Ctf7), to establish cohesion between sister chromatids during DNA replication. Genes \& Dev. 13: 320-333.

Uhlmann, F. and Nasmyth, K. 1998. Cohesion between sister 
chromatids must be established during DNA replication. Curr. Biol. 8: 1095-1101.

Uhlmann, F., Wernic, D., Poupart, M.A., Koonin, E.V., and Nasmyth, K. 2000. Cleavage of cohesin by the CD clan protease separin triggers anaphase in yeast. Cell 103: 375-386.

Waizenegger, I.C., Hauf, S., Meinke, A., and Peters, J.M. 2000. Two distinct pathways remove mammalian cohesin from chromosome arms in prophase and from centromeres in anaphase. Cell 103: 399-410.

Walter, J.C. 2000. Evidence for sequential action of cdc7 and cdk2 protein kinases during initiation of DNA replication in Xenopus egg extracts. J. Biol. Chem. 275: 39773-39778.

Walter, J. and Newport, J.W. 1997. Regulation of replicon size in Xenopus egg extracts. Science 275: 993-995.

Walter, J. and Newport, J. 2000. Initiation of eukaryotic DNA replication: Origin unwinding and sequential chromatin association of Cdc45, RPA, and DNA polymerase $\alpha$. Mol. Cell 5: 617-627.

Walter, J., Sun, L., and Newport, J. 1998. Regulated chromosomal DNA replication in the absence of a nucleus. Mol. Cell 1: 519-529.

Watrin, E., Schleiffer, A., Tanaka, K., Eisenhaber, F., Nasmyth, K., and Peters, J.M. 2006. Human Scc4 is required for cohesin binding to chromatin, sister-chromatid cohesion, and mitotic progression. Curr. Biol. 16: 863-874.

Yanow, S.K., Gold, D.A., Yoo, H.Y., and Dunphy, W.G. 2003. Xenopus Drf1, a regulator of Cdc7, displays checkpoint-dependent accumulation on chromatin during an S-phase arrest. J. Biol. Chem. 278: 41083-41092.

Yoshizawa-Sugata, N., Ishii, A., Taniyama, C., Matsui, E., Arai, K.I., and Masai, H. 2005. A second human Dbf4/ASK-related protein, Drf1/ASKL1, is required for efficient progression of S and M phases. J. Biol. Chem. 280: 13062-13070.

Zegerman, P. and Diffley, J.F. 2007. Phosphorylation of Sld2 and Sld3 by cyclin-dependent kinases promotes DNA replication in budding yeast. Nature 445: 281-285.

Zou, L. and Stillman, B. 2000. Assembly of a complex containing Cdc45p, replication protein $\mathrm{A}$, and $\mathrm{Mcm} 2 \mathrm{p}$ at replication origins controlled by S-phase cyclin-dependent kinases and Cdc7p-Dbf4p kinase. Mol. Cell. Biol. 20: 3086-3096. 


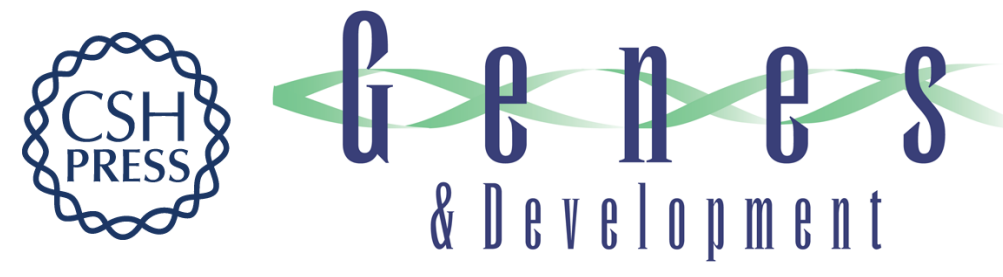

\section{Cdc7-Drf1 kinase links chromosome cohesion to the initiation of DNA replication in Xenopus egg extracts}

Tatsuro S. Takahashi, Abhijit Basu, Vladimir Bermudez, et al.

Genes Dev. 2008, 22:

Access the most recent version at doi:10.1101/gad.1683308

Supplemental http://genesdev.cshlp.org/content/suppl/2008/07/01/22.14.1894.DC1
Material

References This article cites 79 articles, 38 of which can be accessed free at:

http://genesdev.cshlp.org/content/22/14/1894.full.html\#ref-list-1

License

Email Alerting Receive free email alerts when new articles cite this article - sign up in the box at the top

Service

right corner of the article or click here.

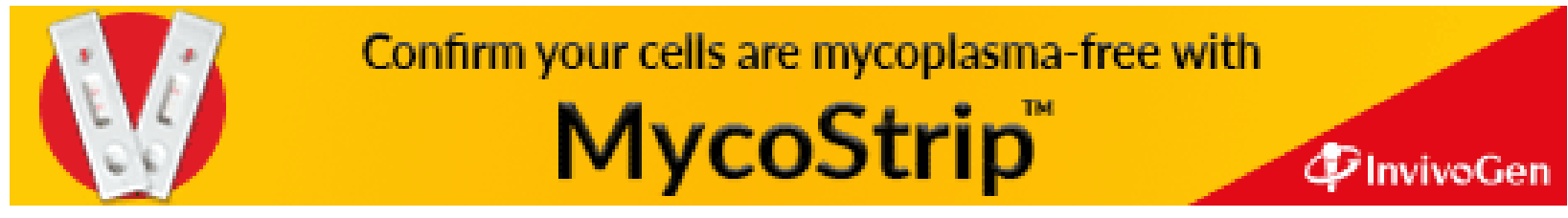

